\title{
Hemicraniectomy in elderly patients with space occupying media infarction: improved survival but poor functional outcome
}

\author{
M Holtkamp, K Buchheim, A Unterberg, O Hoffmann, E Schielke, J R Weber, F Masuhr
}

\begin{abstract}
Objective-To assess the survival rate and functional outcome in elderly patients with space occupying supratentorial infarction who underwent hemicraniectomy compared with those who received medical treatment alone.

Methods-All patients older than 55 years with space occupying middle cerebral artery (MCA) infarction treated in our clinic between January 1998 and July 1999 were included in this retrospective analysis. Patients were eligible for decompressive surgery if they were younger than 75 and had no severe comorbidity. Hemicraniectomy was performed regardless of the affected hemisphere. All patients were followed up for assessment of functional outcome; data were assessed according to the Barthel index and modified Rankin scale and cover a period of 3 to 9 months after infarction.
\end{abstract}

Results-Twelve out of 24 patients underwent hemicraniectomy. Eight patients who were operated on survived; only one patient died of transtentorial herniation, three other deaths were due to medical complications. None of the survivors had a Barthel score above 60 or a Rankin score below 4 . Nine out of 12 medically treated patients died of transtentorial herniation, one patient died of medical complications. The two surviving patients had a Barthel score below 60 and a Rankin score of 4 . Conclusions-Craniectomy in elderly patients with space occupying MCA infarction improves survival rates compared with medical treatment alone. However, functional outcome and level of independence are poor. Craniectomy in elderly patients should not be performed unless a prospective randomised trial proves beneficial.

(F Neurol Neurosurg Psychiatry 2001;70:226-228)

Keywords: cerebral infarction; elderly patients; hemicraniectomy

Large space occupying infarctions in the middle cerebral artery (MCA) territory have a mortality of up to $80 \%$ even with maximal medical treatment. ${ }^{12}$ This "malignant" character is caused by a perifocal oedema leading to unsustainably raised intracranial pressure (ICP). Clinically, patients exhibit progressive worsening of consciousness and signs of mesencephalic dysfunction; ultimately, death from transtentorial or uncal herniation may be the result. ${ }^{134}$

In the past 20 years, several series have been published about patients who were surgically decompressed for large supratentorial infarctions with clinical and CT signs of raised ICP. ${ }^{5-11}$ Most authors reported excellent survival rates and surprisingly good clinical outcomes (table 1). These positive results were further supported by experimental data from rat models. ${ }^{12}{ }^{13}$ However, in all the patient series except one ${ }^{9}$ mean age was below 50 years.

As the vast majority of stroke victims are older than 50 years, ${ }^{14}$ we compared survival rates and functional outcome after hemicraniectomy in elderly patients with space occupying supratentorial infarctions with those who received medical treatment alone.

Table 1 Studies on hemicraniectomy in space occupying MCA infarction

J R Weber

F Masuhr

Department of

Neurosurgery

A Unterberg

Correspondence to:

Dr M Holtkamp

martin.holtkamp@charite.de

Received 15 May 2000 and in revised form

6 October 2000

Accepted 6 October 2000

\begin{tabular}{|c|c|c|c|c|c|}
\hline Author & Year & No of patients & Mean age (y) & Lethality (\%) & Functional outcome \\
\hline Rengachary et $a l^{11}$ & 1981 & 3 & 31 & 0 & 2 patients $\mathrm{BI}<60 ; 1$ patient $>90 \ddagger$ \\
\hline Kondziolka and Fazl ${ }^{10}$ & 1988 & 5 & 40.1 & 0 & All patients $\mathrm{BI}>60 \ddagger$ \\
\hline Delashaw et $a l^{9}$ & 1990 & 9 & 57 & 11 & 4 patients $\mathrm{BI}>60$ \\
\hline Jourdan et al & 1993 & $7^{\star}$ & NA & 28 & All patients $\mathrm{BI}>60 \neq$ \\
\hline Kalia and Yonas ${ }^{8}$ & 1993 & $4 \dagger$ & 34.3 & 0 & All patients $\mathrm{BI}>60 \ddagger$ \\
\hline Carter et $a l^{6}$ & 1997 & 14 & 49.2 & 21 & 8 patients $\mathrm{BI}>60$ \\
\hline Schwab et ap & 1998 & 63 & 49.7 & 27 & Mean BI 65 \\
\hline
\end{tabular}

^In 7 of 9 patients hemicraniectomy was performed due to ischaemic infarction.

tAll patients underwent strokectomy.

$\ddagger \mathrm{BI}$ scores are estimated following clinical and functional descriptions.

$\mathrm{BI}=$ Barthel index; $\mathrm{NA}=$ not applicable. 
Table 2 Elderly patients with space occupying MCA infarction and hemicraniectomy

\begin{tabular}{|c|c|c|c|c|c|c|c|c|}
\hline \multirow{2}{*}{$\begin{array}{l}\text { Patient } \\
\text { No }\end{array}$} & \multirow[b]{2}{*}{ Age/sex } & \multirow[b]{2}{*}{ Territory of infarction } & \multirow[b]{2}{*}{ Aetiology } & \multirow{2}{*}{$\begin{array}{l}\text { Delay stroke/ } \\
\text { operation }\end{array}$} & \multicolumn{4}{|l|}{ Follow up } \\
\hline & & & & & Time & $B I$ & $R S$ & Living situation \\
\hline 1 & $55, \mathrm{~F}$ & L MCA & Arterial embolus & $30 \mathrm{~h}$ & 8 months & 55 & 4 & Rehabilitation clinic \\
\hline 2 & $56, M$ & $\mathrm{R} \mathrm{MCA} / \mathrm{pACA}$ & Arterial embolus & $25 \mathrm{~h}$ & 4 months & 60 & 4 & Rehabilitation clinic \\
\hline 3 & $58, \mathrm{~F}$ & $\mathrm{R} M C A$ & Carotid dissection & $9 \mathrm{~d}$ & 3 months & 35 & 4 & Home for elderly \\
\hline 4 & $60, \mathrm{~F}$ & R MCA & Arterial embolus & $130 \mathrm{~h}$ & 3 months & 0 & 5 & Nursing home \\
\hline 5 & $60, M$ & R MCA & Arterial embolus & $24 \mathrm{~h}$ & 4 months & 0 & 5 & Nursing home \\
\hline 6 & $67, M$ & L MCA & Atrial fibrillation & $29 \mathrm{~h}$ & t8 months & NA & NA & NA \\
\hline 7 & $67, M$ & $\mathrm{R} \mathrm{MCA} / \mathrm{pACA}$ & Atrial fibrillation & $14 \mathrm{~h}$ & 4 months & 25 & 4 & Rehabilitation clinic \\
\hline 8 & $69, M$ & $\mathrm{R} M C A$ & Cryptogenic & $13 \mathrm{~h}$ & 8 months & 40 & 4 & Day clinic \\
\hline 9 & $70, \mathrm{~F}$ & R MCA/pACA & Atrial fibrillation & $30 \mathrm{~h}$ & †3 months & NA & NA & $\mathrm{NA}$ \\
\hline 10 & $70, \mathrm{M}$ & L MCA/PCA & Atrial fibrillation & $24 \mathrm{~h}$ & $\dagger 17$ days & NA & NA & NA \\
\hline 11 & $73, \mathrm{~F}$ & $\mathrm{R} \mathrm{MCA} / \mathrm{pACA}$ & Atrial fibrillation & $48 \mathrm{~h}$ & †8 days & NA & NA & NA \\
\hline 12 & $74, \mathrm{M}$ & $\mathrm{R} M C A / A C A$ & Perioperative bypass & $100 \mathrm{~h}$ & 9 months & 10 & 5 & Nursing home \\
\hline
\end{tabular}

$\mathrm{p}=$ Partial; $\mathrm{MCA}=$ middle cerebral artery; $\mathrm{PCA}=$ posterior cerebral artery; $\mathrm{ACA}=$ anterior cerebral artery; $\mathrm{NA}=$ not applicable; $\mathrm{BI}=\mathrm{Barthel}$ index; $\mathrm{RS}=\mathrm{Rankin}$ scale; $\mathrm{NA}=$ not applicable. + Patient died at $\mathrm{x}$ days or months.

\section{Patients and methods}

All patients with space occupying supratentorial infarctions older than 55 years treated in our clinic between January 1998 and July 1999 were included in this analysis. Patients were not eligible for hemicraniectomy if they were older than 75 years or had severe medical or neurological comorbidity. All patients were treated conservatively following a fixed protocol with maintenance of a mean arterial pressure of 90-110 $\mathrm{mm} \mathrm{Hg}$, glucose serum concentrations of 5-6 mmol/l, and care for sufficient oxygenation and protection from aspiration.

The decision for surgery was based on a large hypodense infarct demarcation in the MCA territory regardless of lateralisation as visible on cranial CT with a midline shift of 5 $\mathrm{mm}$ or more indicating space occupying oedema. Clinically, deterioration of consciousness as a first sign of rising ICP had to be present. Hemicraniectomy was performed before other clinical signs of herniation. If additional signs of lateral herniation developed before surgery, an antioedematous treatment with mannitol infusions and controlled hyperventilation $\left(\mathrm{paCO}_{2} 30 \mathrm{~mm} \mathrm{Hg}\right)$ was started. Hemicraniectomy was performed with a diameter of at least $12 \mathrm{~cm}$ and an augmented dura plastic was inserted as described previously. $^{5}$

Follow up data of all patients refer to the period of 3 to 9 months after ischaemic infarction. For assessment of clinical outcome and activities of daily living, the Barthel index and modified Rankin scale were used.

\section{Results}

Twelve out of 24 elderly patients with space occupying MCA infarction underwent hemicraniectomy (for summarised data see table 2); four patients were not operated on due to advanced age and eight because of preexisting comorbidity (table 3 ).

The mean (SD) age of the operated patients was 64.9 (6.7) years. Six patients had an ischaemic infarction restricted to the MCA territory, five patients had additional anterior cerebral artery (ACA) and one additional posterior cerebral artery (PCA) infarction. One patient had a progressive stroke, with an interval of 9 days between the initial symptoms and decompressive surgery. Without this patient the average time between onset of symptoms and craniectomy was 42.4 (SD 37.6) hours (range 13-130 hours). Four patients died during the period of follow up, but only one death resulted from transtentorial herniation after progression of an additional partial ACA infarction. Another 70 year old male patient died 17 days after hemicraniectomy from septic circulatory failure and two further patients died, one in a rehabilitation centre and one in a nursing home, presumably from heart failure and pulmonary embolism, respectively.

Of the eight surviving patients operated on $(66 \%)$ none had a Barthel index score above 60 (range 0-60) and no patient had a Rankin score below 4 (range 4-5).

Mean age of the 12 medically treated patients was 72.5 (SD 8.9) years. Nine of these patients $(75 \%)$ died of transtentorial herniation in the first days after infarction. Another

Table 3 Elderly patients with space occupying MCA infarction and medical treatment alone

\begin{tabular}{|c|c|c|c|c|c|c|c|c|}
\hline \multirow{2}{*}{$\begin{array}{l}\text { Patient } \\
\text { No }\end{array}$} & \multirow[b]{2}{*}{ Age/sex } & \multirow[b]{2}{*}{ Territory of infarction } & \multirow[b]{2}{*}{ Aetiology } & \multirow{2}{*}{$\begin{array}{l}\text { Contraindication for } \\
\text { hemicraniectomy }\end{array}$} & \multicolumn{4}{|l|}{ Follow up } \\
\hline & & & & & Time & $B I$ & $R S$ & Living situation \\
\hline 1 & $57, \mathrm{~F}$ & L MCA/ACA & Paraneoplastic coagulopathy & Lung cancer & $\dagger 2$ days & NA & NA & NA \\
\hline 2 & $60, \mathrm{~F}$ & L MCA/bilat. ACA & Bilateral ICA occlusion & Bilateral ACA infarction & $\dagger 7$ days & NA & NA & NA \\
\hline 3 & $69, \mathrm{~F}$ & L MCA & L ICA occlusion & Previous disabling strokes & $\dagger 8$ days & NA & NA & NA \\
\hline 4 & $70, \mathrm{~F}$ & L MCA & Atrial fibrillation & Coronary heart disease & +5 days & NA & NA & NA \\
\hline 5 & $72, \mathrm{~F}$ & L MCA/ACA & Atrial fibrillation & Cardiac disease & $\dagger 3$ days & NA & NA & NA \\
\hline 6 & $72, \mathrm{M}$ & Bilateral $\mathrm{MCA} / \mathrm{pACA}$ & Atrial fibrillation & Bilateral MCA infarction & $\dagger 4$ days & NA & NA & NA \\
\hline 7 & $73, \mathrm{M}$ & L MCA & Atrial fibrillation & Cardiac disease & 8 months & 10 & 4 & Nursing home \\
\hline 8 & $74, \mathrm{M}$ & L MCA & Cryptogenic & Cardiac disease & 9 months & 25 & 4 & Nursing home \\
\hline 9 & $75, \mathrm{M}$ & L MCA/ACA & L ICA occlusion & Advanced age & †1 day & NA & NA & NA \\
\hline 10 & $77, \mathrm{M}$ & L MCA/ACA & Atrial fibrillation & Advanced age & $\dagger 3$ days & NA & NA & NA \\
\hline 11 & $79, \mathrm{~F}$ & R MCA/ACA & Atrial fibrillation & Advanced age & $\dagger 5$ days & NA & NA & NA \\
\hline 12 & $92, \mathrm{~F}$ & $\mathrm{R} \mathrm{MCA} / \mathrm{pACA}$ & Atrial fibrillation & Advanced age & $\dagger 12$ days & NA & NA & NA \\
\hline
\end{tabular}

$\mathrm{p}=$ Partial; $\mathrm{MCA}=$ middle cerebral artery; $\mathrm{ACA}=$ anterior cerebral artery; $\mathrm{ICA}=$ internal carotid artery; $\mathrm{BI}=\mathrm{Barthel}$ index; RS=Rankin scale; $\mathrm{NA}=\mathrm{not}$ applicable. †Patient died at $\mathrm{x}$ days. 
patient died shortly after ischaemia of pneumonia. The two surviving patients had Barthel index scores of 25 and 10 and Rankin score of 4.

\section{Discussion}

Current data suggest that hemicraniectomy is an effective treatment for large space occupying MCA infarctions in terms of survival rate and functional outcome. Indeed, mortality from herniation was low in our group of patients operated on, although overall mortality increased to $33 \%$ due to nonneurological complications. In line with published data on conservatively treated patients, mortality due to transtentorial herniation was much higher in the non-operated patients $(75 \%) .^{12}$

During follow up, none of the surviving patients, either surgically or medically treated, showed a Barthel index score above 60 and a Rankin score below 4; this indicates severely disabled and completely dependent patients in both groups. The poor functional results in the surgically treated patients contrast markedly with all other studies of hemicraniectomy for space occupying supratentorial infarctions..$^{5-11}$

Factors with possible influence on the outcome-other than advanced age-may be the high proportion of patients with additional ACA or PCA infarctions or a delay between onset of symptoms and decompressive surgery.

In our series, six patients operated on had combined MCA/ACA or MCA/PCA infarctions. However, only one death in these patients could be attributed to herniation. In the surviving subgroup, the three patients with combined infarctions did not show worse Barthel index scores compared with the five patients with isolated MCA infarctions. In a recent large hemicraniectomy study, ${ }^{5}$ more than one third of patients had combined infarctions, but no negative impact on the functional outcome in this subgroup was reported. These findings argue against a major negative influence of combined infarctions on the outcome in our series compared with others.

Previous studies suggest a better outcome of patients treated with early rather than delayed hemicraniectomy. ${ }^{6}{ }^{11}$ However, no inverse correlation between time to surgery and outcome was detected in our patients. The average delay of 42 hours was shorter than in most earlier studies. ${ }^{6-11}$ Thus, the poor outcome in our series cannot be explained by a delay between stroke and hemicraniectomy.

In summary, advanced age is the only differing variable when comparing our patients who were operated on with earlier investigations. Although mortality from herniation was low after hemicraniectomy, clinical outcome and level of independence were poor. Even the patient with the best Barthel index score of 60 still needed massive assistance for his daily life. Our data suggest that in elderly patients with large space occupying supratentorial infarctions decompressive surgery should not be performed.

1 Hacke W, Schwab S, Horn M, et al. Malignant middle cerebral artery territory infarction. Clinical course and prognostic signs. Arch Neurol 1996;53:309-15.

2 Berrouschot J, Sterker M, Bettin S, et al. Mortality of spaceoccupying (malignant) middle cerebral artery infarction under conservative intensive care. Intensive Care Medicine 1998;24:620-3

3 Wijdicks EFM, Diringer MN. Middle cerebral artery territory infarction and early brain swelling: progression and tory infarction and early brain swelling: progression and

4 Ropper AH, Shafran B. Brain edema after stroke. Clinical syndrome and intracranial pressure. Arch Neurol 1984;41: syndro.

5 Schwab S, Steiner T, Aschoff A, et al. Early hemicraniectomy in patients with complete middle cerebral artery infarction. Stroke 1998;29:1888-93.

6 Carter BS, Ogilvy CS, Candia GJ, et al. One-year outcome after decompressive surgery for massive non-dominant hemispheric infarction. Neurosurgery 1997;40:1168-76.

7 Jourdan C, Convert J, Mottolese C, et al. Evaluation of the clinical benefit of decompression hemicraniectomy in intracranial hypertension not controlled by medical treatment. Neurochirugie 1993;39:304-10.

8 Kalia KK, Yonas H. An aggressive approach to massive middle cerebral artery infarction. Arch Neurol 1993;50: 1293-7.

9 Delashaw JB, Broaddus WC, Kassel NF, et al. Treatment of right hemispheric cerebral infarction by hemicraniectomy. Stroke 1990;21:874-81.

10 Kondziolka D, Fazl M. Functional recovery after decompressive craniectomy for cerebral infarction. Neurosurgery 1988;23:143-7.

11 Rengachary SS, Batnitzky S, Morantz RA, et al. Hemicraniectomy for acute massive cerebral infarction. Neurosurgery 1981;8:321-8.

12 Engelhorn T, Doerfler A, Kastrup A, et al. Decompressive craniectomy, reperfusion, or a combination for early treatment of acute "malignant" cerebral hemispheric stroke in rats? Stroke 1999;30:1456-63.

13 Doerfler A, Forsting M, Reith W, et al. Decompressive craniectomy in a rat model of "malignant" cerebral hemispheric stroke: experimental support for an aggressive hemispheric stroke: experimental support for an ag

14 Williams GR, Jiang JG, Matchar DB, et al. Incidence and occurrence of total (first-ever and recurrent) stroke. Stroke 1999;30:2523-8. 